Original Research Article

\title{
Development of software for prediction and virtual screening of antioxidant activity of new synthesized azaheterocyclic compounds
}

\author{
Victor P. Ryzhenko ${ }^{1}$, Igor F. Belenichev ${ }^{2}$, Iryna B. Samura ${ }^{2 *}$, Oleksii A. Ryzhov ${ }^{1}$
}

${ }^{1}$ Department of Medical and Pharmaceutical Informatics and Innovative Technologies, ${ }^{2}$ Department of Pharmacology and Medical Formulation, Zaporizhzhia State Medical University, Zaporizhzhia, Ukraine

Received: 22 March 2019

Revised: 15 April 2019

Accepted: 03 May 2019

*Correspondence to:

Dr. Iryna B. Samura,

Email:irinasamura77@ gmail.com

Copyright: (C) the author(s), publisher and licensee Medip Academy. This is an openaccess article distributed under the terms of the Creative Commons Attribution NonCommercial License, which permits unrestricted noncommercial use, distribution, and reproduction in any medium, provided the original work is properly cited.

\begin{abstract}
Background: Increasing introduction of innovation technologies into medicine and pharmacology makes it possible to modify and develop further the methods of the development of new medicines. Such methods include virtual screening. In this article approaches to building software for virtual screening of nitric oxide (NO)scavengers in an important class of azaheterocyclic compounds are discussed.

Methods: During the study period (from October 2017 to January 2019) the methods for the evaluation of antioxidant activity, as well as quantum-mechanical and statistical calculations were conducted. Quantum-mechanical calculations on HOMO (highest occupied molecular orbital) energy and LUMO (lowest unoccupied molecular orbital) energy descriptors have been conducted using program complex WinMopac 7.2.

Results: Evaluation methods of antioxidant activity, quantum-mechanical and statistical calculations have been presented. The algorithm for computer program of virtual screening has been proposed. Prospects and benefits of computer modeling of agent activity are considered.

Conclusions: Establishment of computer program for virtual screening will significantly reduce time and resources during researching new synthesized compounds. The algorithm for a computer program of virtual screening has been developed Predictable antioxidant activity data on nitric oxide radical (NO-)inhibition may be calculated in percentage using HOMO and LUMO as the input data for this program.
\end{abstract}

Keywords: Antioxidant activity, Descriptors, Molecular modeling, Virtual screening

\section{INTRODUCTION}

Development of new highly efficient and safe medicines is based on currently existing material and information resources. More than 160 million of organic compounds have been synthesized and are available today in the form of samples for testing biological activity. ${ }^{1}$ The search for the new promising pharmacologically active substances is the multicriteria process since it is necessary to ensure the existence of the target specific activity along with a minimum of adverse and toxic effects and acceptable pharmacokinetic characteristics of the potential drug as well. Pilot testing of millions of organic compounds for thousands of types of biological activity is not practically feasible at the present stage, which necessitates the application of computer methods to optimize the scanning of new pharmacologically active substances. ${ }^{2}$

Computer molecular modeling is a new but very promising and rapidly developing discipline. Computational chemistry involves attempting to calculate numerical properties of molecules, the most common in the 
biochemical sciences being molecular energies. Interest in such aprioristic studies is related the possibility of virtual searching for compounds with desired properties that significantly reduces the number of required expensive experimental procedures. Molecular modeling is one of the key approaches in the drug discovery and development process. The common feature of molecular modeling methods is the atomic level of description of the molecules that includes treating atoms as the smallest individual unit with the corresponding coordinates, interacting according to certain rules (a molecular mechanics approach), or modeling electrons of each atom (a quantum chemistry approach). This model is the starting point for the design of molecular properties. ${ }^{3}$

Over the last decades in science it was realized the fact that unlimited growth in the size of synthesized and tested compound libraries does not only bring by itself to intensification of research programs, but even can lead to unjustified additional expenses. ${ }^{4}$ Obviously a comprehensive synthesis and analysis of a huge number of compounds are extremely labor-intensive and economically inexpedient solution. The task is complicated many fold in the case of application of multistage synthetic methods, multicomponent reactions, and parallel combinatorial schemes as well. Therefore, even in relatively simple cases, the researcher has to resort to another experimental design for the rational selection of candidate compounds for synthesis and subsequent tests. In this example as well as many other contemporary design practices, application of techniques for rational presynthetic selection that may significantly reduce the number of samples of diverse screening compounds with required properties are a necessary condition for successful implementation of research programs to develop new drugs. There has been emerged and gradually gaining the practical value computer, or virtual screening, a relatively new discipline that is becoming an essential tool in assisting fast and cost-efficient drug discovery and optimization. $^{5-8}$

Virtual screening combines computational power to the biochemical space to streamline drug discovery, design, development, and optimization. Computer drug design for active compounds has become an essential tool within the drug development pipeline..$^{9-11}$

The aim of the present study was to describe approaches to the development of a computer program for the virtual screening of nitrosyl radicals in a series of azaheterocycles.

\section{METHODS}

In the process of our study there were carried out the quantum-mechanical calculations for descriptors HOMO energy (highest occupied molecular orbital) and LUMO energy (lowest unoccupied molecular orbital) using the computer program WinMopac7.2. ${ }^{12}$ Structural optimization was achieved using a semi-empirical method AM1 with the following parameters:
Calculation $=$ SinglePoint, WaveFunction $=$ ClosedShell (RHF). ${ }^{13}$

Then there were refractive index data $(\omega)$ calculated. ${ }^{14}$ There was conducted the estimate of antioxidant activity (AOA). ${ }^{15}$ The method is based on sodium nitroprusside photoinduction model accompanied by nitrosyl radicals (NO·) accumulation. NO induction was performed by the action of light on sodium nitroprusside $\mathrm{Na}_{2}[\mathrm{Fe}(\mathrm{NO})(\mathrm{CN}) 5] \times 2 \mathrm{H}_{2} \mathrm{O}$ in vitro. ${ }^{16}$ There were calculated the indicators of AOA.

Principle of the method. Photoinduction of sodium nitroprusside is accompanied by the accumulation of NO. radical, which if judged by the rate of ascorbate oxidation by measuring the optical density of the sample at $265 \mathrm{~nm}$.

Conducting research. Ex tempore $0.08 \%$ solution of ascorbic acid and $0.6 \%$ solution of sodium nitroprusside were prepared. $1 \mathrm{ml}$ of ascorbic acid and $0.5-1 \mathrm{ml}$ of investigated compounds $(\mathrm{C}=10-6 \mathrm{~mol} / \mathrm{l})$ were added to 2 $\mathrm{ml}$ of sodium nitroprusside.

After mixing the reaction was started by immersion from a $300 \mathrm{~W}$ light source with $\lambda=425 \mathrm{~nm}$ for $30 \mathrm{~min}$. AOA was estimated by maintaining the concentration of ascorbic acid, which was determined at $\lambda=265 \mathrm{~nm}$.

AOA was calculated by the formula:

$$
\mathrm{AOA}=\frac{\mathrm{D}_{\mathrm{K}}-\mathrm{D}_{\mathrm{O}}}{\mathrm{D}_{\mathrm{K}}} \times 100 \%
$$

Where: $D_{K^{-}}$optical density of samples without any substances; $D_{O^{-}}$optical density of test sample. ${ }^{17}$

Statistical analyses was conducted using STATISTICA 6.0 software for Windows. ${ }^{3}$ The data are presented as mean values for sample \pm standard error of the mean. The validity of the differences between the experimental groups was assessed using Student's criterion and Fisher's criterion.

\section{RESULTS}

Quantum-mechanical calculations have shown that the refractive indices $(\omega)$ of investigated compounds were within the limits from- $1.9605 \mathrm{eV}$ to $-2.9398 \mathrm{eV} .{ }^{18}$ It was found that the data of HOMO and LUMO indices of these compounds are also places at a high level. The investigated compounds had high indices of AOA that in most cases exceeded the standard. The research has demonstrated that the data of AOA of the investigated compounds were within 49.43-82.16\% (in concentration 10-3mol/l) (Table 1).

In the concentration of $10^{-5}$ mole/l the indicators of AOA of almost all compounds have reduced, but nevertheless they exceeded the standard. 
When decreasing concentration to $10^{-7}$ mole/l antioxidant properties were found to decrease, but, nevertheless, all the compounds have demonstrated activity that exceeded the standard index.

Table 1: Antioxidant activity of the investigated compounds (n=5) according to inhibition of NO•-radical $(\mathrm{M} \pm \mathbf{m})$.

\begin{tabular}{|c|c|c|c|c|c|c|}
\hline \multirow{2}{*}{ Compound } & \multicolumn{2}{|l|}{$10^{-3} \mathrm{~mol} / /$} & \multicolumn{2}{|l|}{$10^{-5} \mathrm{~mol} / \mathrm{l}$} & \multicolumn{2}{|l|}{$10^{-7} \mathrm{~mol} / \mathrm{l}$} \\
\hline & $\mathbf{E}, \mathbf{M} \pm \mathbf{m}$ & $\%$ & $\mathbf{E}, \mathbf{M} \pm \mathbf{m}$ & $\%$ & $\mathbf{E}, \mathbf{M} \pm \mathbf{m}$ & $\%$ \\
\hline 1 & $1.514 \pm 0.066^{2}$ & 56.57 & $1.115 \pm 0.040^{2}$ & 15.30 & $1.532 \pm 0.057^{2}$ & 58.43 \\
\hline 2 & $1.564 \pm 0.054^{2}$ & 61.73 & $1.233 \pm 0.084^{1}$ & 27.50 & $1.585 \pm 0.081^{2}$ & 63.91 \\
\hline 3 & $1.525 \pm 0.055^{2}$ & 57.70 & $1.323 \pm 0.059^{2}$ & 36.81 & $1.357 \pm 0.079^{2}$ & 40.33 \\
\hline 4 & $1.54 \pm 0.074^{2}$ & 59.25 & $1.133 \pm 0.089$ & 17.16 & $1.464 \pm 0.08^{2}$ & 51.39 \\
\hline Control & & & $0.967 \pm 0.054$ & & & \\
\hline 5 & $1.603 \pm 0.089^{1}$ & 82.16 & $1.408 \pm 0.079^{1}$ & 60.00 & $1.385 \pm 0.051^{1}$ & 57.38 \\
\hline 6 & $1.562 \pm 0.082^{1}$ & 77.50 & $1.506 \pm 0.091^{1}$ & 71.13 & $1.356 \pm 0.107^{1}$ & 54.09 \\
\hline 7 & $1.439 \pm 0.077^{1}$ & 63.52 & $1.376 \pm 0.076^{1}$ & 56.36 & $1.371 \pm 0.074^{1}$ & 55.79 \\
\hline 8 & $1.532 \pm 0.065^{1}$ & 74.09 & $1.383 \pm 0.067^{1}$ & 57.16 & $1.396 \pm 0.083^{1}$ & 58.63 \\
\hline Control & & & $0.880 \pm 0.024$ & & & \\
\hline 9 & $1.532 \pm 0.055^{2}$ & 58.43 & $1.072 \pm 0.084$ & 10.86 & $1.565 \pm 0.088^{2}$ & 61.84 \\
\hline 10 & $1.445 \pm 0.123^{2}$ & 49.43 & $0.987 \pm 0.094$ & 2.07 & $1.544 \pm 0.093^{2}$ & 59.67 \\
\hline Control & & & $0.967 \pm 0.054$ & & & \\
\hline 11 & $1.417 \pm 0.056^{1}$ & 61.02 & $1.515 \pm 0.074^{1}$ & 72.16 & $1.369 \pm 0.045^{1}$ & 55.57 \\
\hline Control & & & $0.880 \pm 0.024$ & & & \\
\hline NAC & $0.901 \pm 0.092$ & 2.46 & $1.042 \pm 0.087$ & 18.47 & $0.981 \pm 0.074$ & 11.53 \\
\hline Control & & & $0.880 \pm 0.024$ & & & \\
\hline
\end{tabular}

Note: ${ }^{1} \mathrm{p}<0.05$ relative to control; ${ }^{2} \mathrm{p}<0.01$ relative to control.

Thus, it was discovered that all the investigated compounds possessed antioxidant properties in vivo model of sodium nitroprusside photoinduction due to their nitric oxide radical scavenging activity. In the comparison of the values of the calculated descriptors with data obtained in vitro, it was found to exist linear dependence of AOA on the values HOMO and LUMO. ${ }^{19}$

In the analysis run of the results of the research it was demonstrated that AOA of the compounds studied to be dependent on the refractive index (Figure 1).



Figure 1: Dependence of AOA on refractive index.
Virtual screening includes quite a number of computer methods and algorithms, which permit implementation of pre-synthetic selection of organic ligands for the stage of synthesis and biological testing, and also help to predict many pharmacological characteristics of molecules. In this connection it was decided to conduct the determination of the probable activity of compounds being based on linear interpolation.

On the basis of the data received from monitoring and assessment of different levels of AOA, the program algorithm was proposed for virtual screening.

The data that will be entered by the researcher:

Researcher calculates the indicators of HOMO and LUMO of the substances investigated using program complex WinMopac7.2 or a similar one. Indicators of HOMO and LUMO are the input data.

The absolute hardness indicator is calculated as:

$$
\eta=\frac{E(L U M O)-E(H O M O)}{2}
$$

The absolute electrical negativity indicator is calculated as: 


\section{$E(L U M O)+E(H O M O)$ \\ 2}

The refractive index indicator is calculated as:

$\omega=\chi^{2} / 2 \eta$

Data to be entered into the program (database):

Refractive index (of the compound investigated)

Antioxidant activity (calculated empirically)

Correlation coefficient (of the compound investigated) is calculated as:

$K_{1}=\frac{\mathrm{AOA}_{1}}{\omega_{1}}$

Total correlation coefficient:

$K=\frac{K_{1}+K_{\mathbf{z}}+K_{\mathrm{a}} \ldots+K_{n}}{n}$

Predictable antioxidant activity is determined as

$\mathrm{AOA}=K$

\section{DISCUSSION}

In our previous research it was shown that the data of HOMO and LUMO indices of azaheterocyclic compounds as well as their refractive indices are placed at a high level. ${ }^{18,19}$ The azaheterocyclic compounds demonstrate also high indices of AOA that in most cases exceeded the standard. ${ }^{17}$

Table 2: Quantum mechanical calculations of some xanthinyl-7-acetic acid derivatives.

\begin{tabular}{|llll|}
\hline Compound & $\begin{array}{l}\mathrm{E}(\mathrm{LUMO}), \\
\mathrm{eV}\end{array}$ & $\begin{array}{l}\mathrm{E}(\mathrm{HOMO}), \\
\mathrm{eV}\end{array}$ & $\boldsymbol{\omega}, \mathbf{e V}$ \\
\hline 1 & -0.662058 & -8.85597 & -2.7640 \\
\hline 2 & -0.621876 & -9.09988 & -2.7869 \\
\hline 3 & -0.664048 & 8.88114 & -2.7719 \\
\hline 4 & -0.617553 & -9.10999 & -2.7855 \\
\hline 5 & 0.175988 & 8.35553 & -1.9605 \\
\hline 6 & -0.166582 & -8.11534 & -2.1572 \\
\hline 7 & -0.825065 & -8.38973 & -2.8062 \\
\hline 8 & -0.683878 & -8.14727 & -2.6123 \\
\hline 9 & -0.551883 & -8.55349 & -2.5903 \\
\hline 10 & -0.848165 & -8.85555 & -2.9398 \\
\hline 11 & -0.738576 & $-8,81243$ & $-2,8246$ \\
\hline
\end{tabular}

As a result of the algorithm application it is possible to create software for virtual screening of NO scavengers in a series of azaheterocycles. A computer program will determine the predictable antioxidant activity of compounds investigated in percentage as a result of its work (Table 2). As input data the HOMO and LUMO indicators will be used (Figure 2)

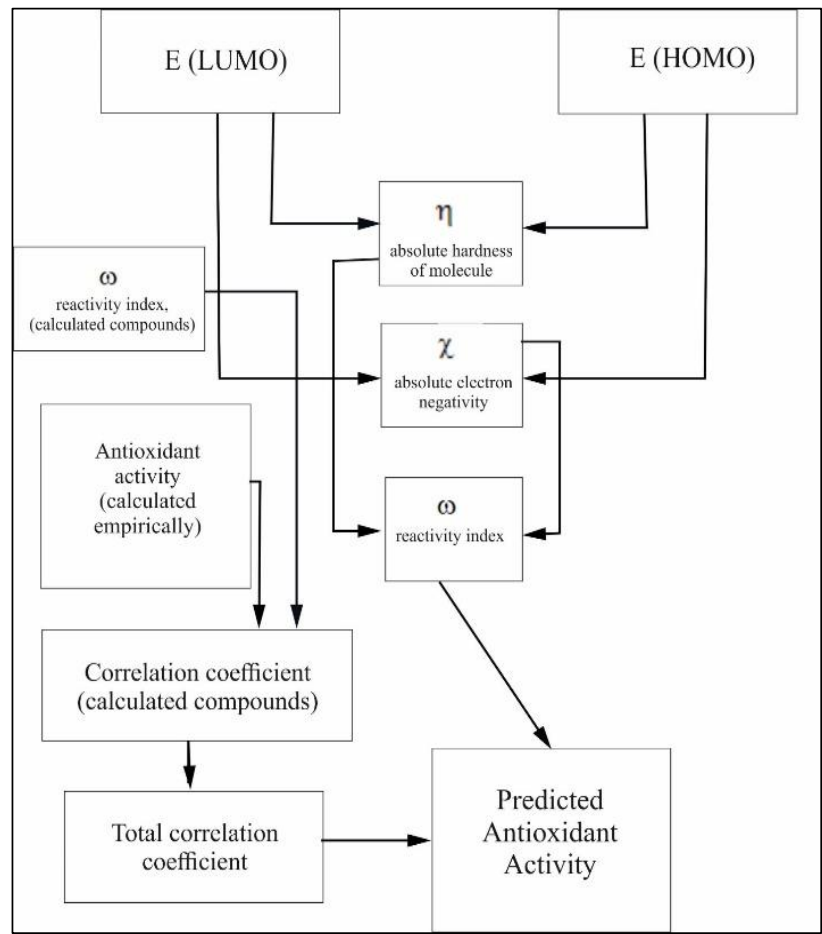

Figure 2: Algorithm for computer program for virtual screening of NO scavengers Ina series of azaheterocycles.

It is best to implement the program as a web application as this solution will help to reduce the time and cost of software testing. In the future, this implementation will attract more users than fixed version. As a result, the requirement for pre-synthetic analysis of virtual libraries of compounds for the rational selection of structures, the most promising in the light of the specific challenges of the coming pilot testing of their antioxidant activity is clearly seen.

The computer based prediction of compound binding antioxidant activities will be one of the most time and cost efficient methods for screening ligand libraries that enrich results of search for potential antioxidant drugs.

Brief description of the program for the virtual screening of scavengers of active forms of oxygen and nitrogen. Web- application to determine the predictable antioxidant activity of chemical compounds is given in the programming language Python.

The calculated quantum-chemical indices of HOMO and LUMO are used as the input information. As a result of program calculations we have an indicator of reactive 
index. Based on the reactive index, the antioxidant activity is calculated according to the correlation coefficient.

\section{Structural elements of the program}

- Database of quantum-chemical parameters and the geometric structure of the reference drugs

- Electron-topological matrix for the study of compounds.

- Working database with information about the electronic structure of compounds.

- Software system for predicting the antioxidant activity in relation to the active forms of oxygen and nitrogen.

The predicted indicator of antioxidant activity established in percentage serves as the initial data.

\section{CONCLUSION}

The development of a computer program for virtual screening of antioxidant activity will significantly reduce the time and resources when researching new synthesized azaheterocyclic compounds. Predictable results of antioxidant activity could be obtained in percentage, using HOMO and LUMO indicators as input data.

Funding: No funding sources

Conflict of interest: None declared

Ethical approval: The study was approved by the Institutional Ethics Committee

\section{REFERENCES}

1. Kim S, Thiessen PA, Cheng T, Yu B, Bolton EE. An update on PUG-REST: RESTful interface for programmatic access to PubChem. Nucleic Acids Res. 2018 Jul 2;46(W1):W563-W570.

2. Filimonov DA, Lagunin AA, Gloriozova TA, Rudik AV, Druzhilovskii DS, Pogodin PV, et al. Prediction of the biological activity spectra of organic compounds using the PASS online web resource. Chem Heterocyclic Compounds. 2014 Jun 1;50(3):444-57.

3. Zaitsev VM, Liflyandskii VG, Marinkin VI. Prikladnaya meditsinskaya statistika [Applied Medical Statistics]. 2 ${ }^{\text {nd }}$ Ed:Foliant;2006:144-164.

4. Bohm HJ, Schneider G. Virtual screening for bioactive molecules. $1^{\text {st }}$ Ed. Weinheim:Wiley-VCH;2000;10.

5. Walters WP, Stahl MT, Murcko MA. Virtual screening- an overview. Drug Disc Today. 1998;21(3):160-78.

6. Alvarez J., Shoichet B., Virtual Screening in Drug Discovery. $1^{\text {st }}$ Ed. CRC Press, Taylor \& Francis Group;2005:496.

7. Klebe G, Virtual Screening: An Alternative to High Throughput Screening? Kluwer Academic Publisher; 2002;20(1):171-90.
8. Varnek A, Tropsha A. Chemoinformatics Approaches to Virtual Screening. $1^{\text {st }}$ Ed. RSCPublishing;2008:120-149.

9. Merlot C, Domine D, Cleva C, Church DJ. Chemical substructures in drug discovery. Drug Discov Today.2003;13(8):594-602.

10. Willett P. Chemical Similarity searching. J Chem Inf Comput Sci.1998;38(6):983-96.

11. Patani GA, LaVoie EJ. Bioisosterism: a rational approach in drug design. Chem Rev. 1996;96(3):314776.

12. Shchepin R. WinMOPAC 7.2 Download (Free)winmo.exe. Software Informer. 2019 [cited 20 May 2019]. Available at: https://winmopac.software.informer.com/7.2/Dewar

13. M.J.S., Zoebisch E.G., Healy E.F., Stewart J.P. AM1: A New General Purpose Quantum Mechanical Molecular Model. J American Chem Society. 1985;107(13):3902-9.

14. Ishihara M, Wakabayashi H, Motohashi N, Sakagami H. Estimation of relationship between the structure of trihaloacetylazulene derivatives determined by a semiempirical molecular-orbital method (PM5) and their cytotoxicity. Anticancer Res. 2010 Mar;30(3):837-41.

15. Deniz M, Borman H, Seyhan T, Haberal M. An effective antioxidant drug on prevention of the necrosis of zone of stasis: N-acetylcysteine. Burns. 2013 Mar;39(2):320-5.

16. Vanin AF. Dinitrosyl iron complexes and Snitrosothiols are two possible forms for stabilization and transport of nitric oxide in biological systems. Biochemistry (Mosc). 1998 Jul;63(7):782-93.

17. Belenichev IF, Cherny VI, Kolesnyk Yu M. Rational neuroprotection. Ukraine. Donetsk: Publish. House Zaslavsky; 2008:232-264.

18. Ryzhenko VP, Ryzhov OA, Belenichev IF, Levich SV. Study of dependence of xanthine derivatives NOscavenger properties from energy descriptors. Biol Markers Guided Ther. 2018;5(1):37-46.

19. Ryzhenko V, Belenichev I, Ryzhov O, Levich S. Experimental and theoretical approaches to the creation of computer program for virtual screening of scavengers NO in a range of azageterocycles. Med Informatics Engineering. 2018;3:54-7.

Cite this article as: Ryzhenko VP, Belenichev IF, Samura IB, Ryzhov OA. Development of software for prediction and virtual screening of antioxidant activity of new synthesized azaheterocyclic compounds. Int J Basic Clin Pharmacol 2019;8:12926. 